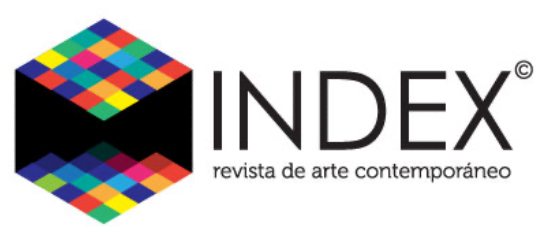

No. 10. DIC 2020

ISSN: 2477-9199

Dossier

DOI: $10.26807 /$ cav.vi10.374

\title{
EN CARNE PROPIA: INVESTIGACIÓN Y PRÁCTICA ARTÍSTICA FEMINISTA DESDE LA AUTOETNOGRAFÍA
}

\section{IN OWN FLESH: RESEARCH AND FEMINIST ARTISTIC PRACTICE FROM AUTOETHNOGRAPHY}

Marla Freire Smith

\section{Resumen}

El artículo presenta y analiza un fragmento de obra visual desde la autoetnografía como metodología de trabajo aplicada al campo de las artes visuales. A partir del método semiótico, epistemología feminista, teoría crítica y autoetnografía, realizo un análisis interpretativo de obras de performance e instalaciones relevantes dentro de mi investigación y práctica artística realizada entre los años 2003 y 2019. Desde el análisis de estas obras, se presenta la autoetnografía como una metodología de trabajo que permite desarrollar de forma conjunta investigación y práctica artística.

Palabras clave: investigación artística, práctica artística, feminismos, autoetnografía, epistemología feminista, artivismo, interdisciplina

\section{Abstract}

The article analyzes a fragment of visual work that used the methodology of autoethnography applied to the field of the visual arts. Using the semiotic method, feminist epistemology, critical theory and autoethnography, I carry out an interpretive analysis of relevant performance works and installations within my research and artistic practice between 2003 and 2019. With this analysis, autoethnography is presented as a methodology work that allows to develop joint research and artistic practice. 
Keywords: artistic research, artistic practice, feminism, autoethnography, feminist epistemology, interdiscipline

\section{Biografía de la autora}

Marla Freire Smith (Quilpué, Chile, 1981) es artista visual e investigadora en arte y cultura. Dra. en Historia y Teoría del Arte por la Universidad Autónoma de Madrid, es académica en la carrera de Licenciatura en Artes en la Universidad Autónoma de Chile. En su investigación y práctica artística se evidencian cruces entre arte contemporáneo, feminismos, artivismos y autoetnografía.

Código de identificación ORCID: https://orcid.org/0000-0003-1831-5417

Introducción (o cómo teorizar la obra propia: el camino recorrido)

Explicitar a relación entre teoría y práctica artística en ocasiones puede resultar difícil, y más, cuando se crea y acciona para luego traducir a un lenguaje académico aquello que surge desde la reflexión, pero también desde lo intuitivo, lo nómade y lo simbólico. Justamente, conceptos cuestionados a la hora de generar conocimientos. Por otro lado, son esos conceptos los que se presentan en la dimensión experiencial y constituyen aprendizajes (García-Huidobro, 2019). Evidentemente, al realizar investigación guiada por la práctica artística, estos conceptos se vuelven centrales, pues se valora el desarrollo o proceso tanto como la obra final. Y si pensamos en la práctica artística, ensayo y error constantes permiten avanzar y construir conocimiento, siendo un espacio donde se funden saber y no saber. 
Desde reflexiones en esta línea, la relación con aquello que (me) disciplina y somete, se vuelve central a la hora de analizar mi práctica artística. Esto, porque de una u otra forma, los posicionamientos teóricos y filosóficos son puestos en jaque, los puntos de fuga son abiertos (sino creados) y las tensiones afloran. Aquí es dónde conviene revelar uno de los motivos de este estudio: evidenciar cómo la autoetnografía se me ha presentado como una estrategia metodológica que me ha permitido realizar investigación desde mi práctica artística. Ante ello, escribir este texto en primera persona es una de las claves, desde la autobiografía (Iniesta y Feixa, 2006) como puntapié inicial, que permite situarme como creadora, pero también como teórica e historiadora del arte, creando tensiones no habituales en este campo de generación de conocimiento, donde los roles están clásicamente definidos desde la propia institucionalidad: artista, historiador/a del arte, curador-a/comisario/a de arte, teórico/a del arte, etc.

En esta búsqueda de definiciones, y en esta necesidad de reconocer e instalar mi práctica artística como investigación, es que doy con una reflexión que me ayuda a clarificar algunos conceptos base, como por ejemplo que a través la autobiografía es posible leer una sociedad (Iniesta y Feixa, 2006). Desde esta mirada, la autobiografía es un punto de partida, pero me resultaba un poco cerrada como metodología porque no considera necesariamente el campo social y político, temas que cruzan de forma transversal mis obras y pueden ser leídas desde ahí, por distintas personas y comunidades. Por ello, pensar mi práctica artística desde la autoetnografía como metodología de trabajo se vuelve la mejor estrategia, pues tal y como señala Mercedes Blanco (2012b): "una manera de ver a la autoetnografía es ubicándola en la perspectiva epistemológica que sostiene que una vida individual puede dar cuenta de los contextos en los que le toca vivir a esa persona (...)” (p. 54). Dicho así, se abre entonces un campo de trabajo mixto, donde me resulta posible pensar como creadora, escribir como artista, crear como teórica, etc. pudiendo abrirse otros cuantos, como si se tratase de una papiroflexia que permite, en base a dobleces, crear formas alternativas de generación de conocimientos.

Para llevar adelante este estudio he planteado una metodología de trabajo basada en dos direcciones: por un lado, está la revisión de fuentes bibliográficas primarias y secundarias, y por otro, el análisis de obra a través del método semiótico (Agudelo, 2014; Eco, 2007; Klinkenberg, 2006; Peirce, 1998) para focalizarme en la interpretación de un fragmento de mi 
producción artística realizada entre los años 2003 y 2019. Quiero señalar que no pretendo realizar un listado de todas las obras creadas en dicho período y mucho menos generar un análisis exhaustivo: aquí es donde entra en valor la relectura de obras como un corpus, desde la autoetnografía (Blanco, 2012 a y b; Denzin, 1989; Denzin y Lincoln, 2003; Ellis y Bochner, 1996; Iniesta y Feixa, 2006; entre otros) como metodología de trabajo en artes visuales. A ella se suma la teoría crítica (Flórez, 2015; Maffía, 2004; Tabares, 2019; Trebisacce, 2016) que permite plantear lecturas y abrir miradas hacia la investigación artística, contemplando fuentes variadas y multidisciplinares, como por ejemplo, la epistemología feminista (Alcoff y Potter, 1993; Blázquez, Flores y Ríos, 2012; Bartra, 2012; Harding, 1986, entre otras). De estas revisiones, surge la deconstrucción como concepto clave que permite observar los cuestionamientos y reflexiones presentes en mi práctica e investigación artística.

Desde esto ejes, el objetivo general es analizar, interpretar y establecer vínculos entre las obras presentadas y lo social/político, desde la autoetnografía como metodología de trabajo, evidenciando que la práctica artística se constituye como investigación. De acuerdo con esto, surgen las siguientes preguntas: ¿qué posibilidades presenta reflexionar la práctica artística como investigación a partir de la autoetnografía como metodología de trabajo?, ¡es posible considerar las propias experiencias como motores creadores que permiten vincular práctica artística e investigación?, ¿¿dónde comienza o termina la investigación y la práctica artística? Ante estas interrogantes, la idea central es que la autoetnografía permite dar un marco conceptual para repensar la práctica artística como proceso de investigación que tiene sus propias coordenadas de inscripción y posicionamiento, $y$, en base a ello, generar vínculos o puentes con la comunidad desde la teoría y el diálogo.

\section{En primera persona: un relato autobiográfico reflexivo}

Mercedes Blanco (2012 a y b) y Martyn Hammersley (2008) afirman que la investigación autoetnográfica propone distinguir desde dónde $-\mathrm{y}$ hasta dónde—llega lo científico y/o lo literario. Inevitablemente, ello supone situarnos desde la interdisciplina, pues las fronteras entre una y otra se funden y surgen otras aristas, como me ha ocurrido, por ejemplo, con la teoría crítica (Maffía, 2004; Tabares, 2019; Trebisacce, 2016) y la 
epistemología feminista (Alcoff y Potter, 1993; Anderson y Zinsser, 1991; Harding, 1986). Aquí es cuando las reflexiones se van situando como ejes de investigación que llevan hacia disciplinas como las ciencias sociales (Fernández, 2018; Flórez, 2015; Lugones, 2008, Segato, 2016, Tabares, 2019, Varela, 2019) y en ocasiones, la filosofía (Bartra, 2012; Blázquez, 2012; Herner, 2009). A ello se añaden por supuesto, miradas con un componente político dentro de la estética y las artes (Aladro-Vico, Jivkova-Semova y Bailey, 2018; Klinkenberg, 2006). Pero hacer este cambio de mirada e ir incorporando saberes que se traducen en imágenes (y luego leer las imágenes resultantes para traducirlas a conceptos e investigaciones en el sentido tradicional) nos remite a la idea de redescubrimiento constante, pues tal como señala Denzin (2008): "estamos en un momento de descubrimientos y redescubrimientos conforme nuevas formas de ver, interpretar, argumentar y escribir están siendo debatidas y discutidas" (cit. en: Blanco, 2012 a).

Este cambio de mirada nos lleva a pensar los procedimientos para comprender que se está investigando mientras se crea. A este respecto, Cristopher Frayling (1993) señala distintas claves para poder referirnos a la investigación sobre arte: acerca del arte/diseño, desde el arte/diseño y la práctica de ambas. Por otro lado, Ignacio Villegas (2018) señala que Pierre Baqué establece tres estados de la investigación vinculadas al arte: "sobre las artes (...) por las artes (...) investigación en artes (...)” (p. 24). Esto es importante de revisar, pues tal como señala Villegas (2018):

el arte genera conocimiento a partir de sus componentes, entendidos como aspectos concomitantes en la producción sémica de una obra: su procedimiento de producción física; su forma/imagen; sus temas o su contexto, todo lo cual permite valorar la práctica como factor procedimental para la respuesta a preguntas de un investigador en un campo determinado (p. 23).

Esto, que puede parecer un detalle metodológico, es un procedimiento constructivo (o deconstructivo, dicho en clave feminista) que podríamos señalar como un llamado al cambio de paradigma en lo que refiere a la construcción de conocimientos. Al entender la práctica artística como investigación, se tejen saberes en unión con otras disciplinas que dejan como resultado la obra misma. Esto permite graficar que cada proceso de realización de obra significa también construcción de conocimiento (he ahí la importancia del recorrido: ensayo y error constantes, 
pero también reflexión y resolución de problemas). Aquí es cuando pienso en lo señalado por Rosario García-Huidobro (2019) respecto del aprendizaje artístico, al señalar que se trata de: "un aprendizaje que permite actuar en otras disciplinas y contextos bajo un pensamiento rizomático, abierto y flexible" (p. 179). Si bien la autora se refiere a la educación en artes, considero que es plausible pensarlo también en el terreno de la investigación artística propia, que también (y, por cierto) constituye aprendizaje. Es decir, nos referimos a un proceso de investigación y estudio permanentemente inacabado, donde identifico a lo menos dos momentos que van alternándose: el detonante creativo (cuando surgen las ideas iniciales, bocetos y pruebas técnicas) y su conceptualización (búsqueda de fuentes y fundamentación de la obra). Ambos, inevitablemente devienen en preguntas y diálogos que se abren constantemente. Nuevamente, la idea de la papiroflexia se hace patente.

\section{De las obras y su relación con lo social/político: lecturas que se desprenden}

En el año 2003 comienzo la práctica artística que guía mi investigación hasta hoy, uniendo artes visuales, feminismos y comunidad. La instalación que da inicio al recorrido se titula "Parto" y corresponde a una escultura fabricada en papel maché que presenta unas piernas ( 1,5 x 1,5 x 2,0 metros) sujetas a un muro, que calzaban un par de zapatos rojos y parían un metro y medio de cabellos míos mezclados con el de distintas personas con quienes tenía algún vínculo. Cuando hice esta obra, fue luego de haber tomado la decisión de quitar mi apellido paterno. Evidentemente la obra gráfica ese nuevo nacer, al tiempo que reflexiona acerca de las omisiones de las mujeres, del poder de nombrar y evidencia el derecho al autorreconocimiento. Digo esto porque fue una década completa en la que tuve que usar sistemáticamente un nombre social para poder lograr el reconocimiento legal, obtenido finalmente en el año 2014. Cabe señalar que con esta acción estaba ejerciendo abiertamente el poder de nombrar (algo históricamente impedido a las mujeres) y al situar mi apellido materno como el principal (mi segundo apellido también es de una mujer) de forma simbólica estaba poniendo de manifiesto las omisiones, empezando por las que componen nuestro propio nombre, y, por extensión, quienes somos. Esta obra marca mi recorrido en las artes, y, de una u otra forma, deriva en que formalmente continuara estudios en historia y teoría del arte, para visibilizar a mis colegas y contribuir a que sus nombres y obras no fuesen omitidos, al menos 
desde la historia del arte y en cada escenario que me fuera posible accionar. Por supuesto, estos temas se conversaban cada vez que la obra o su registro era expuesto.

De esa primera obra se desprenden los zapatos, que fueron multiplicados al año siguiente para ser instalados en muros de galerías y centros de arte, hasta que en el año 2005 había fabricado cincuenta de ellos en papel maché y fueron expuestos bajo el título de "Lilith", en la Galería de Arte de la Pontificia Universidad Católica de Chile, siendo parte de la exposición colectiva "De otro lugar", curada por Nancy Gewölb. Esta obra nuevamente volvía sobre la desobediencia a causa de la palabra, al llamarse como la primera mujer bíblica, posteriormente omitida en el mismo relato. Nuevamente el poder de la palabra era el centro de la reflexión y los zapatos ejemplificaban distintas inflexiones, al ser instalados en los muros de la galería como si caminaran por ellos, venciendo la gravedad. Paralelamente suceden algunos hitos: por un lado, realizo un trabajo de performance a través de la creación del alter ego "Eva Meretriz" (2004-2006), para reflexionar acerca de la figura judeocristiana de Lilith en diversas acciones que consistían en comer una manzana roja frente al público vestida de un traje confeccionado con cabellos (los mismos que componían la primera obra). De esta forma, se evidencia que el centro de mi trabajo seguía siendo el lenguaje y las filiaciones (a propósito del trabajo con el cabello) y siempre desde una perspectiva feminista.

Con el tiempo, el tema de las omisiones y borraduras adquieren fuerza y me llevan a denunciar los femicidios. Surge así la performance "Ni una más" (obra ganadora en el Festival de Performance Ensemble of Women, 2007) una obra donde me centraba en el grado máximo de violencia hacia las mujeres, pero sin olvidar aquella que, soterrada y disfrazada bajo el concepto de tradición o cultura, también se manifiesta (Segato, 2016). A través de "Ni una más" (figura 1) buscaba posicionar esto, así como denunciar la impunidad y las escasas políticas públicas en esta materia. Cabe señalar que esta obra fue realizada tres años antes de que en Chile se realizara una modificación a la Ley de Violencia Intrafamiliar ( $\left.{ }^{\circ} 20066\right)$ dando origen a lo que hoy se conoce como Ley de Femicidio ( $\left.{ }^{\circ} 20480\right)$, que sigue siendo insuficiente porque la definición que utiliza es acotada y no contempla variantes. 
$\mathrm{Al}$ año siguiente, viajo a España para continuar estudios y llevo conmigo la instalación "Lilith", para transformarla en una intervención urbana bajo el título de "Camino al andar" (2008-2010), un proyecto desarrollado junto a Davixo Berimbá en las ciudades de Madrid, Milán y Lisboa. Con esta intervención dispuesta en calles y monumentos, evidenciaba la falta de reconocimiento a las mujeres en la esfera pública, en espacios de poder y en la memoria de las ciudades. De esta forma, el recorrido, personal y político se refleja en las obras y abre diálogos, mientras insisto en la utilización de mi apellido materno y me hago consciente de que este acto de desobediencia es entendido como un desacato social y político.

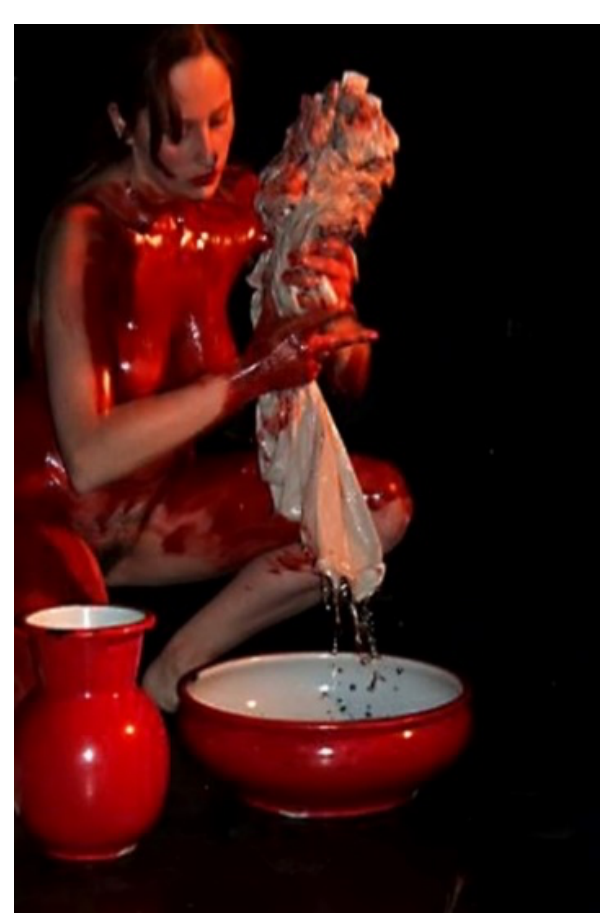

Figura 1. "Ni una más”, 2007

Fotografía: Davixo Berimbá 


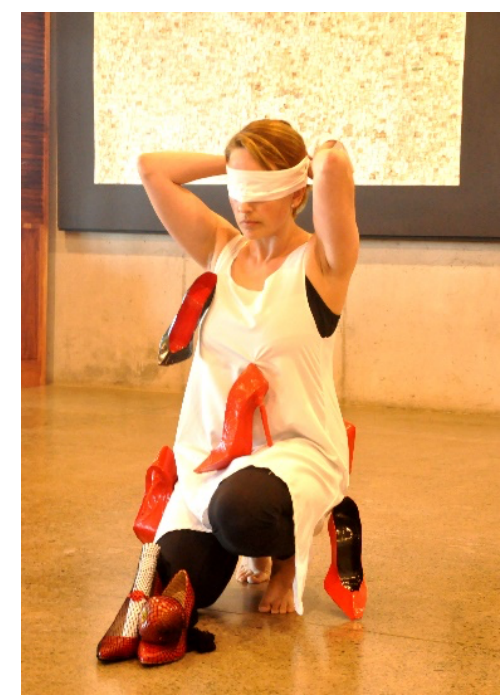

Figura 2. "Pacta Sunt Servanda”, 2017

Fotografía: Davixo Berimbá

De regreso en Chile y una vez legalizado el cambio de nombre en ambos países (Chile y España) presento en el año 2017 la performance "Pacta Sunt Servanda (Lo pactado obliga)" (figura 2) realizada en el Parque Cultural de Valparaíso, dentro de la Muestra de performance “Ejercicios de Realidad” organizada por Perfolink. En la obra hago pública, por primera vez, la Sentencia Judicial, firme y ejecutoriada, que ordena a las reparticiones estatales reconocer y hacer efectivo el cambio de apellidos. Aun cuando han transcurrido varios ańos, el lenguaje sigue siendo el centro y dos años después realizo la performance "Ni una más II (2007-2019)" en el IV Festival CuerpAs, organizado por Perfolink. En esta obra vuelvo sobre aquella realizada en 2007, para realizar un memorial con los nombres y edades de las 739 mujeres asesinadas desde ese año y hasta el día de la performance (16 de noviembre de 2019). Cabe señalar que la necesidad de hacer esta obra es porque varios de estos nombres no son considerados en los listados ni cifras oficiales del Estado, que trabaja con una definición de femicidio muy acotada y les deja fuera (menores de edad, suicidios feministas, disidencias, etc.). Cabe señalar que esta obra, y el festival, son realizados en medio del estallido social, comenzado casi un mes antes en Chile. 
En este punto y al realizar un recorrido por mi práctica artística, toman sentido las reflexiones de Eli Bartra (2012) en especial cuando afirma que: "el quehacer feminista dentro de las ciencias y las humanidades construye caminos que le son propios para conocer la realidad" (p. 69). En efecto, estos saberes feministas se han hecho presentes y constantes cada vez, desde aquella primera obra en el año 2003. Es lo que hoy me hace pensar en lo planteado por Sandra Harding (1986) respecto del proceso de generación de conocimiento, donde distingue tres elementos: epistemología, método y metodología. De forma esclarecedora, Norma Blázquez (2012) se centra en las características de cada una de ellas y menciona como una de las principales críticas feministas a la epistemología tradicional, el hecho de que "esas teorías del conocimiento se basan en el Punto de vista masculino del mundo” (p.23). En cuanto al método, señala que la diferencia radica en que las formas de obtener y analizar la información pueden "diferir mucho de las elecciones de una persona que hace ciencia de manera tradicional con un punto de vista masculino" (p. 23). Respecto de la metodología, señala que ésta: "elabora, resuelve o hace funcionar las implicaciones de la epistemología para llevar a cabo o poner en práctica un método" (p. 23). De esta forma se evidencia que, a través del cuestionamiento de los marcos establecidos para interpretar la realidad, es posible deconstruir las lecturas que han dominado los discursos. Cabe recalcar que estos elementos (y cuestionamientos) se hacen presente en mi práctica artística y devienen posteriormente en investigaciones en torno a los feminismos y dialogan con las obras: desde preguntas que movilizan hipótesis (o supuestos) hasta reflexiones que evocan respuestas estéticas y que pueden devenir en/desde la experiencia. De esta forma, desde la autoetnografía como metodología de trabajo, se abren las vivencias personales al punto que una comunidad pueda leerlas, interpretarlas y conmoverse, al punto de generar cambios. En estas coordenadas se enmarca mi práctica artística, donde tal como señala Ellis (1999) respecto de la autoetnografía: "las distinciones entre lo personal y lo cultural se vuelven borrosas” (p. 673). Reflexión similar propone Richardson (2003) reforzando esta idea: "Las autoetnografías son altamente personalizadas, textos reveladores en los cuales los autores cuentan relatos sobre su propia experiencia vivida, relacionando lo personal con lo cultural” (p. 512). Desde aquí se construye mi práctica e investigación artística, que evidencia además uno de los puntos de fuga enunciados por Foucault (1979) respecto de los saberes sometidos. Y es que la investigación y 
práctica artística son situadas constantemente dentro de aquellos saberes por una óptica positivista, que busca someterlas bajo diversos dispositivos de generación y reproducción de valor que operan como sistemas de legitimación del saber. Conocimientos y saberes artísticos son situados bajo los de otras disciplinas, a través de jerarquías de conocimientos y desde la violencia epistémica, sin entender que las investigaciones artísticas suceden desde otras aristas que cuestionan el paradigma positivista en la construcción de conocimiento.

\section{$A$ modo de conclusiones}

En el recorrido presentado, la autorreflexividad se vuelve un proceso clave, donde preguntas, reflexiones, saberes y diálogos se conectan. Y por supuesto, afloran cuestionamientos a través de la voz propia, que pone el punto de partida en lo autobiográfico para llevarlo al plano social a través de la autoetnografía, generando tensiones en las formas/modos habituales de hacer investigación. Si se considera lo señalado por Denzin (1989) respecto de que el método biográfico (y autobiográfico) es interpretativo, podemos inferir que, al trabajar desde la autoetnografía, esto se mantiene, pero que se potencia el mensaje al conectar lo personal con lo cultural, tal como señalan Ellis y Bochner (2000). De esta forma, si las vivencias orientan el trabajo creador en artes visuales, las experiencias que lo movilizan se amplifican al documentarlo y analizarlo desde la autoetnografía como metodología de trabajo, permitiendo vínculos con otros y con la comunidad, al encontrar resonancia y abrir diálogos. Así, la autoetnografía en el trabajo artístico difumina fronteras entre lo personal y lo cultural, abre espacios de diálogos entre experiencias movilizadas desde las artes, y, por ello, evidencia el potencial de la práctica artística como investigación e incluso como movilizador de cambios. Plantear la creación/investigación artística de esta forma es una estrategia que permite proponer la generación de conocimiento desde formas no habituales, prescindiendo incluso de aquellas estrategias tradicionales basadas en la constatación de resultados y objetivos concretos y medibles. De esta manera, la autoetnografía como metodología de trabajo en la práctica e investigación artística abre posibilidades de construcción de conocimiento colectivas, genera 
diálogos y probablemente, abra también nuevas posibilidades epistemológicas que aún no hemos siquiera imaginado.

\section{Referencias}

Agudelo, P. (2014). Hacia una semiótica del arte. Implicaciones del pensamiento peirceano en el estudio del arte contemporáneo. Cuadernos de Filosofía Latinoamericana. Vol. $35, \mathrm{~N}^{\circ} 111,2014$, p. 127-145.

Alcoff, L., Potter, E. (ed.). (1993). Feminist Epistemologies. New York, London: Routledge.

Aladro-Vico, E. Jivkova-Semova, D., Bailey, O. (2018). Artivismo: Un nuevo lenguaje educativo para la acción social transformadora. Comunicar, Revista científica de Comunicación y Educación. https://bit.ly/33Xuaeu (27-08-2020).

Anderson, B., Zinsser, J. (1991) Historia de las mujeres: una historia propia. Barcelona: Editorial Crítica.

Anderson, L. (2006). Analytic Autoethnography, en Journal of Contemporary Ethnography. https://bit.ly/32Vl8Pu $(22-09-2020)$.

Bartra, E., (2012). Acerca de la investigación y la teoría feminista. En: Blázquez, N., Flores, F., y Ríos, M. (2012). Investigación feminista: epistemología, metodología y representaciones sociales. p. 67-77.

Blanco, M. (2012 a). ¿Autobiografía o autoetnografía? Desacatos. (38). p. 169-178.

Blanco, M. (2012 b). Autoetnografía: una forma narrativa de generación de conocimientos. Andamios, 9 (19), p. 49-74.

Blázquez, N., Flores, F., y Ríos, M. (coord.). (2012). Investigación feminista: epistemología, metodología y representaciones sociales. México: Universidad Nacional Autónoma de México. 
Denzin, N. (1989). Interpretive Biography. Qualitative Research Methods, vol. 17. California: Sage.

Denzin, N., Lincoln, Y. (2003). Introduction: The Discipline and Practice of qualitative Research, en: Norman D., Lincoln, Y. (eds.), Strategies of Qualitative Inquiry. California: Sage, p. 1- 44. https://bit.ly/3cpcVq7 (17-09-2020).

Eco, U. (2007). Perspectivas de una semiótica de las artes visuales. Criterios (25-28), p. 221 233.

Ellis, C. (1999). Heartful Autoethnography. Qualitative Methods Conference, Qualitative Health Research, vol. 9, California: Sage. p. 669-683.

Ellis, C. y Bochner, A. (eds.). (1996). Composing Ethnography: Alternative Forms of Qualitative Writing. California: Altamira Press.

Ellis, C., Bochner, A. (2000). Autoethnography, Personal Narrative, Reflexivity: Researcher as Subject. En: Denzin, N., Lincoln, Y. (eds.), Collecting and Interpreting Qualitative Materials. California: Sage. p. 733-768.

Fernández, L. (2012). Género y ciencia: entre la tradición y la transgresión. En: Blázquez, N., Flores, F., y Ríos, M. (2012). Investigación feminista: epistemología, metodología y representaciones sociales. p. 79-110.

Flórez, J. (2015). Lecturas emergentes: Subjetividad, poder y deseo en los movimientos sociales. Bogotá: Editorial Pontificia Universidad Javeriana.

Foucault, M. (1979). La microfísica del poder. Madrid: La Piqueta.

Frayling, C. (1993). Research in art and design. Royal College of Art Research Papers series. London: Royal College of Art.

Freire, M. (2003). Parto [instalación]. Centro Cultural de Viña del Mar. Chile 
Freire, M. (2005). Lilith [instalación]. Galería de Arte Centro de Extensión Pontificia

Universidad Católica de Chile. https://marlafreire.cl/web/lilith/ (01-12-2020).

Freire, M. (2004-2006). Eva Meretriz [instalación/ performance]. Sala Lautaro Rosas, Facultad de Arte Universidad de Playa Ancha, Valparaíso, Chile.

Freire, M. (2007). Ni una más [Performance]. Festival Ensemble of women, Centro Cultural Matucana100, Santiago de Chile. https://marlafreire.cl/web/ni-una-mas/ (3011-2020).

Freire, M. (2008-2010). Camino al andar [instalación]. Calles de Madrid, Milán y Lisboa.

Freire, M. (2017). Pacta Sunt Servanda [Performance]. Ejercicios de memoria, Parque Cultural de Valparaíso, Chile. https://marlafreire.cl/web/pacta-sunt-servanda/ (30-112020).

Freire, M. (2019). Ni una más II (2007-2019) [Performance]. Festival Internacional de Performance CuerpAs, Valparaíso, Chile. https://bit.ly/3lndiV7 (01-12-2020).

García-Huidobro, R. (2019). Experiencias del saber pedagógico de mujeres artistas-docentes. Santiago de Chile: Editorial Cuarto Propio.

Hammersley, M. (2008). Questioning Qualitative Inquiry: Critical Essays. Los Ángeles: Sage

Harding, S. (1986). The Science Question in Feminism. New York: Cornell University Press, Ithaca.

Herner, A. (2009). Territorio, desterritorialización y reterritorialización: un abordaje teórico desde la perspectiva de Deleuze y Guattari. Revista Huellas no 13, p. 160-171. https://bit.ly/3mGpm5A (19-09-2020).

Iniesta, M., Feixa, C. (2006). Historia de vida y ciencias sociales. Entrevista a Franco Ferraroti. Periféria: Revista de Recerca i Formació en Antropología, núm. 5, Universitat Autónoma de Barcelona, España. https://bit.ly/2RR5LRW (22-09-2020) 
Klinkenberg, J. M. (2006). Manual de semiótica general. Bogotá: Universidad de Bogotá Jorge Tadeo Lozano.

Lugones, M. (2008). Colonialidady género. Tabula Rasa. https://bit.ly/2FRqC5k (21-8-20).

Maffia, D. (2004). Contra las dicotomías: feminismo y epistemología crítica. Instituto Interdisciplinario de Estudios de Género. https://bit.ly/32TvJus (07-08-2020)

Peirce, C. S. (1998). The essential Peirce. Selected philosophical writings, vol. 2 (1893-1913). The Peirce Edition Project. Bloomington e Indianapolis: Indiana University Press.

Segato, R. (2016). La guerra contra las mujeres. Madrid: Traficantes de sueños. https://bit.ly/33P48K5 (19-08-2020).

Tabares, C. (2019). Teorías críticas feministas. Transgresoras, creativas: una contribución a los desafíos de la teoría social en América Latina. NORUS. Vol. 7, nº 11. Jun/Jul, p. 85-112. https://bit.ly/35Umkoq (07-08-2020).

Trebisacce, C. (2016). Una historia crítica del concepto de experiencia de la epistemología feminista. Revista Cinta de Moebio. Santiago de Chile, n. 57.

Varela, N. (2019). Feminismo 4.0 La Cuarta Ola. Barcelona: S.A. Ediciones B.

Villegas, I. (2018). Práctica artística como investigación: su instalación y desarrollo en el sistema académico chileno. Revista de Estudios en Sociedad, Artes y Gestión Cultural Tercio Creciente, 7, Nro. 13, enero 2018. https://bit.ly/33TCyv9 (2108-2020).

Enviado: 2020-10-05

Aceptado: 2020-12-06 